\title{
Global constraints on net primary production and inorganic carbon supply during glacial and interglacial cycles
}

\author{
Josep L. Pelegrí, ${ }^{1,2}$ Patricia De La Fuente, ${ }^{1}$ Roger Olivella, ${ }^{1}$ and Antonio García-Olivares ${ }^{1}$ \\ Received 26 October 2012; revised 1 August 2013; accepted 12 November 2013; published 16 December 2013.
}

[1] Relaxation-type models have good skill at reproducing glacial-interglacial transitions in climatic variables. Here we propose a simple two-box and two-state relaxation-type model for the upper ocean (surface and permanent thermocline layers) where dissolved inorganic carbon/nutrients are supplied by the deep ocean and through remineralization within the upper ocean. The model is tuned using genetic algorithms to simulate the atmospheric $\mathrm{CO}_{2}$ time series for the last four glacial-interglacial cycles. The fit to the data is very good, with correlations above 0.8 , as the upper ocean responds to shifts in (1) the intensity of the meridional overturning circulation, from off to on during the glacial-interglacial transition, and (2) the size and sign of net primary production, with respiration greatly exceeding primary production during interglacial periods and production larger than respiration during the glacial phase. The glacial-interglacial transitions are interpreted as shifts between two distinct metabolic states of the Earth system, with high/low supply of dissolved inorganic carbon and nutrients to the productive upper ocean during interglacial/glacial periods.

Citation: Pelegrí, J. L., P. De La Fuente, R. Olivella, and A. García-Olivares (2013), Global constraints on net primary production and inorganic carbon supply during glacial and interglacial cycles, Paleoceanography, 28, 713-725, doi:10.1002/2012PA002419.

\section{Introduction}

[2] The Earth system has presented an alternation between glacial and interglacial states during the last circa $3 \mathrm{Myr}$ [e.g., Imbrie et al., 1993; Sigman and Boyle, 2000; Paillard, 2001; Raymo and Nisancioglu, 2003; Sigman et al., 2010]. These two states display substantial changes in diverse global variables, such as high/low atmospheric $\mathrm{CO}_{2}$ values during interglacial/glacial periods [e.g., Petit et al., 1999; Siegenthaler et al., 2005; Lüthi et al., 2008]. Considering that the amount of dissolved inorganic carbon (DIC) available in the ocean is much larger than that contained within the atmosphere and biosphere, and given the rates of exchange between these different compartments, it turns out that the oceans are the principal responsible for glacial-interglacial changes in atmospheric $\mathrm{CO}_{2}$ [e.g., Sundquist and Visser, 2003]. Therefore, the main processes that have been invoked to explain these atmospheric variations are thought to operate on the intensity of the physical, biological, and chemical ocean pumps.

[3] The physical pump is traditionally related to seasonal and latitudinal changes in sea surface temperature, as the

\footnotetext{
Additional supporting information may be found in the online version of this article.

${ }^{1}$ Departament d'Oceanografia Física i Tecnològica, Institut de Ciències del Mar, CSIC, Barcelona, Spain.

${ }^{2}$ LINCGlobal, Institut de Ciències del Mar, CSIC, Barcelona, Spain.

Corresponding author: J. L. Pelegrí, Departament d'Oceanografia Física i Tecnològica Institut de Ciències del Mar, CSIC, Passeig Marítim de la Barceloneta, 37-49, E-08003 Barcelona, Spain. (pelegri@icm.csic.es)

(C)2013. American Geophysical Union. All Rights Reserved. 0883-8305/13/10.1002/2012PA002419
}

partial pressure of $\mathrm{CO}_{2}$ within the ocean surface depends largely on temperature [e.g., Siegenthaler and Sarmiento, 1993]. The concept, however, is easily extended to consider actual changes in the content of total DIC within the surface ocean, related to the presence of waters of different origin [Sarmiento and Toggweiler, 1984; Siegenthaler and Wenk, 1984; Toggweiler, 1999]. The biological pump depends directly on variations in net primary production, as it transforms DIC into organic carbon [Broecker, 1982a, 1982b; Sarmiento and Toggweiler, 1984; Knox and McElroy, 1984; Martin, 1990]. Finally, the chemical pump relies on changes in calcium carbonate $\left(\mathrm{CaCO}_{3}\right)$, either due to external fluxes or through the dissolution of carbonate organisms: An increase in carbonate raises the ocean's alkalinity which affects the partition of DIC and leads to the sequester of atmospheric $\mathrm{CO}_{2}$ [Broecker, 1982a; Broecker and Peng, 1987]. All three pumps rely, to a large degree, on the rate at which bottom waters (relatively cold, nutrient rich and DIC rich) are brought in contact with the atmosphere, i.e., they rely on the intensity of the meridional overturnning circulation (MOC) [Stommel, 1961; Broecker, 1991].

[4] A number of box-type models, focused on reproducing the interglacial and glacial maximum conditions, have investigated the relative importance of these pumps [e.g., Sarmiento and Toggweiler, 1984; Siegenthaler and Wenk, 1984; Paillard et al., 1993; Toggweiler, 1999; Peacock et al., 2006; Skinner, 2009]. Estimates on the drawdown of $\mathrm{CO}_{2}$ change substantially depending on the diffusive and advective circulation patterns, the assumptions on the conservation and distribution of properties, and whether external factors (such as sediment and dust sources) are allowed. The complexity of a model, and likely its realism, increases with the number of boxes, 
but the large scatter among all results tells us that the relative importance of the mechanisms operating during glacial and interglacial periods remains to be elucidated.

[5] Given the evident difficulty for determining the different contributions during steady state conditions, it is no surprise that time-dependent box models are not used to simulate glacial-interglacial transients. The alternatives are idealized two-state relaxation-type heuristic models for one or more coupled variables [e.g., Calder, 1974; Imbrie and Imbrie, 1980; Watson and Maddock, 1993; Paillard, 1998; Paillard and Parrenin, 2004; Hogg, 2008; García-Olivares and Herrero, 2012, 2013]. These models assume the existence of two different ocean states (glacial and interglacial) and allow DIC, and other oceanic variables, to relax toward different reference values; for example, the control equation for ice volume, $I$, has the form $d I / d t=\left(I_{r}-I\right) / \tau_{\text {ice }}$, where $I_{r}$ is a reference ice volume and $\tau_{i c e}$ is a relaxation time.

[6] The behavior of relaxation models depends on three types of parameters: the timing for the system to switch state, the reference concentrations during each state, and the length of time required for the system to relax toward the reference value. A proper formulation for these parameters requires good knowledge of those mechanisms forcing the behavior of the physical, biological, and chemical pumps, particularly of those processes setting the MOC intensity and the concentration of the transported properties. The parameters may not be constant; for example, the relaxation time typically changes depending on the state and variable under consideration. Many mechanisms have been proposed, such as atmospheric (wind and thermal) forcing, deep ocean stratification, sea ice coverage in the southern ocean, and oscillations in the burial of carbonates [Paillard et al., 1993; Paillard, 1998; Toggweiler, 1999; Stephens and Keeling, 2000; Paillard and Parrenin, 2004; Hogg, 2008; Toggweiler et al., 2006; Skinner, 2009; Garcia-Olivares and Herrero, 2013]. However, no deterministic formulation is yet available so these parameters are usually specified through (properly tuned) heuristic dependences on external and internal forcing.

[7] The Paillard and Parrenin [2004] relaxation-type model illustrates the good skill of heuristic models at reproducing the time series of diverse climatological proxies; Garcia-Olivares and Herrero [2013] have recently optimized the model's formulation to obtain correlations with data as high as 0.90 for ice volume and 0.79 for atmospheric $\mathrm{CO}_{2}$. This model has three time-dependent variables (ice volume, Antarctic ice extent, and atmospheric carbon dioxide), with the reference value for each variable expressed as a linear function that may involve insolation and all three variables. A step-like change of state is specified through an additional dependent variable, efficiency in bottom water formation, which is directly related to ice volume and inversely linked to the amount of insolation over Antarctica and the extent of the Antarctic ice sheet. The argument is that high efficiency implies the formation of salty, well-stratified and high- $\mathrm{CO}_{2}$, bottom waters; when this variable falls below certain threshold, the formation of stratified bottom waters is substantially reduced, and there is a discontinuous increase in the $\mathrm{CO}_{2}$ reference concentration. The Paillard and Parrenin [2004] model has the virtue of identifying the existence of multiple processes and, therefore, represents an important step forward in our understanding of climate transitions. Nevertheless, as in all heuristic arguments, it is unquestionable that there is no unique interpretation for the forcing mechanisms and, furthermore, different versions for the formulations are possible with equally good results [García-Olivares and Herrero, 2012, 2013]. For example, a high rate of deep water formation, no matter how salty and stratified these waters are, implies a fast recirculation of DIC-rich deep waters to the surface. Actually, even a very slow rate of deep water formation would imply relatively short time scales for the MOC, e.g., only one Sverdrup $\left(1 \mathrm{~Sv}=10^{6} \mathrm{~m}^{3} \mathrm{~s}^{-1}\right)$ would fill the world's oceans in a time scale of the order of $10 \mathrm{kyr}$. Therefore, the relevant argument should not focus on the formation of bottom waters but rather on how isolated these waters are, in terms of both negligible diapycnal mixing (because of high vertical stratification) and a small sea-surface print (possibly helped by sea surface ice capping). This brief discussion illustrates that heuristic relaxation-type models are capable of grasping some of the relations between variables and the dependences to external forcing but, as they are not based on fundamental principles, other unknown interactions are certainly possible.

[8] In this study we propose a very simple time-dependent DIC model for an upper ocean that changes at glacialinterglacial time scales. This upper ocean is understood as that part of the ocean holding an active wind- and/or buoyancydriven thermocline circulation and having relatively short (order 10 years) characteristic time scales, connected to a nutrient-rich deep ocean through the MOC. The model, inspired on the way local and remote energy supply allows a living being to sustain transitions between basal and enhanced metabolic states [Pelegrí, 2008], is capable of reproducing the glacial-interglacial transitions with the sole action of a peculiar version of the physical-biological pump. The net autotrophic community production in the upper ocean sets the metabolic rate of the ocean system, sustained through remineralization within the upper ocean (local or proximal reserves) and deep-ocean supply through a changing MOC (remote sources). The results lead us to interpret interglacial periods as times of enhanced metabolic rate, sustained by high heterotrophic respiration (greater than net autotrophic community production) and intense MOC supply, and glacial periods as times when community production exceeds total respiration. An innovative character of the model is the role assigned to the pool of dissolved organic carbon (DOC) in the upper ocean, building up during glacial periods and being consumed during interglacial times, analogous to proximal (and fast) energy reserves in living beings.

[9] The DIC equation arises from conservation arguments in a very simple two-box ocean; therefore, no heuristic interpretations are necessary, its structure being that of a relaxation-type model. The model is tuned with genetic algorithms to hindcast the atmospheric $\mathrm{CO}_{2}$ during the last four interglacial-glacial cycles. It can neither predict the timing when the system switches state nor the reference concentrations during both states, which are set from the data through simple criteria, but finds the size and temporal dependence of the MOC (the inverse of relaxation time) and sets constraints on the amount of primary production and remineralization in the upper ocean.

\section{A Simple Transient Model for the Upper Ocean}

\subsection{Transient Box Model for the Upper Ocean}

[10] Pelegri [2008] has proposed the Earth to be an optimized pulsating system, analogous to many other living 

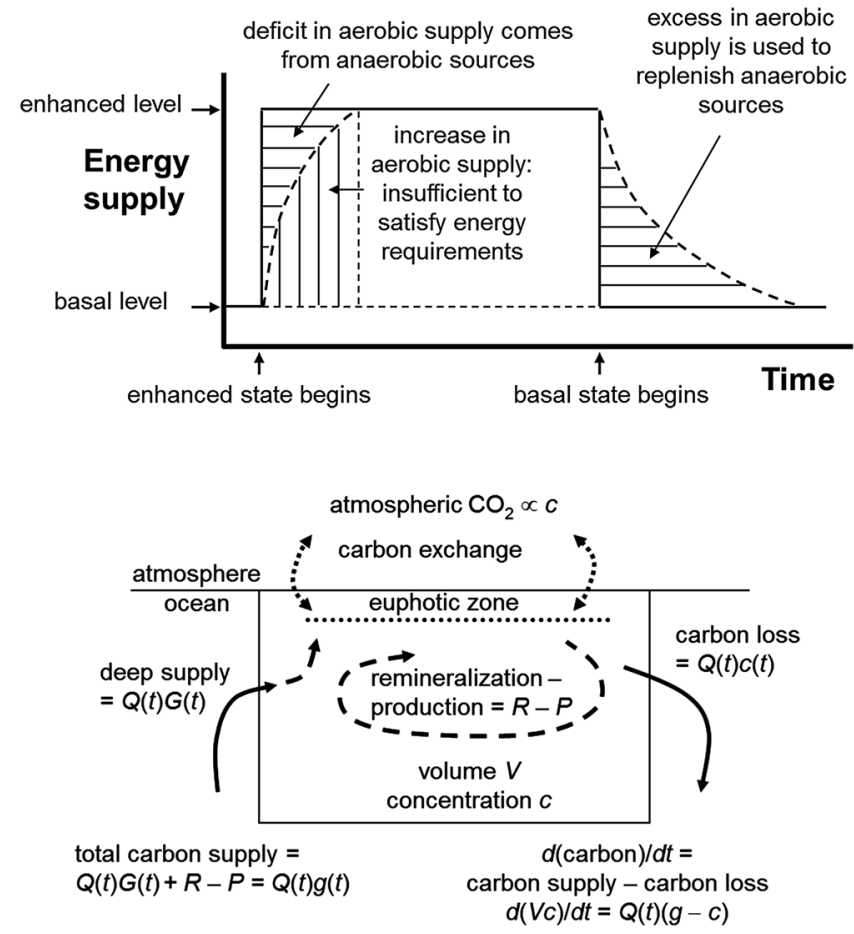

Figure 1. (top) Schematics of the change in energy supply to mammals, as an example of complex system, as it switches from one metabolic state to another. In this plot, the supply discretely changes between two different, low and high, energy supply levels. (bottom) Main elements of the two-box model for DIC concentration in the upper ocean. The closed rectangle represents the upper ocean. The net advective DIC supply is given by $Q(G-c)$ and the aerobic processes $R-P$ account for the deficit or excess supply. Adapted from Pelegri [2008].

beings, and has endorsed the idea that it may be studied using global, physiological-like, variables. In particular, he argued that the glacial and interglacial periods correspond to times of rest and exercise for an autotrophic planet, in terms of its skill to convert solar energy through photosynthesis (see also Appendix A in the supporting information). The efficiency of this conversion is set by the availability of DIC and inorganic nutrients, supplied both through remineralization of DOC in the upper ocean (local and fast sources) and by the MOC advection of nutrient- and carbon-rich deep waters (Figure 1 (top)). In this paper we will further explore these ideas using, as our reference variable, the concentration of DIC in the upper ocean simply because it may be calibrated against the paleorecord of atmospheric $\mathrm{CO}_{2}$. We must keep in mind, however, that DIC is always in excess at the sea surface so that inorganic nutrients, with substantial differences in concentration between the upper and deep ocean, are the truly limiting factors for primary production; hence, hereafter we shall think of carbon as accompanying the nutrient supply in proportions close to the stoichiometric Redfield ratios [e.g., Anderson and Sarmiento, 1994] so that we will indistinctly talk about (inorganic) nutrients or carbon supply.

[11] A complementary view is obtained by considering a simple ocean composed of a time-changing upper box and a deep immutable chamber, as shown in Figure 1 (bottom) [Pelegrí, 2008]. The upper box contains surface and thermocline waters, in direct or indirect contact with the atmosphere, the latter via Ekman or buoyancy pumping [Stommel, 1979; Luyten and Stommel, 1986]. The rate of water recirculation within the upper box is much greater than the rate of water exchange between both compartments; hence, at glacialinterglacial time scales, we consider the upper ocean recirculation to solely be responsible for homogenizing the carbon and nutrient concentrations in the upper box. The upper and deep compartments are connected through the MOC: Water from the upper box sinks into the deep chamber at high latitudes, indistinctly in the Northern and Southern Hemispheres, and eventually recirculates back to the upper ocean. The rate of exchange between the two compartments may change in time through variations in the MOC, shifting between two stable (although not necessarily steady) states [Stommel, 1961].

[12] Temperature, salinity, and alkalinity play no role in our highly idealized two-box model. The arrival of deep waters to the upper compartment only affects its inorganic carbon (and nutrients) content and will bring no other property anomalies. Therefore, we focus on the biological pump related to the transformation of new and remineralized carbon (nutrients), ignoring any changes in air-sea $\mathrm{CO}_{2}$ exchange associated to possible thermodynamic and chemical upper ocean variations. This approach allows us to examine the evolution of DIC in the upper ocean, during the last four glacial-interglacial cycles, solely through the Vostok record of atmospheric $\mathrm{CO}_{2}$. This is because (for constant temperature, salinity, and alkalinity) the relation between DIC in the upper ocean (carbon dioxide, bicarbonate, and carbonate) and atmospheric $\mathrm{CO}_{2}$ is approximately linear in the 180 to $280 \mathrm{ppm} p \mathrm{CO}_{2}$ range (see also Appendix $\mathrm{D}$ in the supporting information).

[13] Obviously, we do not attempt to produce a fully diagnostic model; rather, we propose a conceptual approach that focuses on understanding what the $\mathrm{CO}_{2}$ time series tells us about global constraints on primary production and inorganic carbon supply during glacial and interglacial cycles. Some of the underlying approximations are indeed reasonable; for example, alkalinity does not change through the introduction of $\mathrm{CO}_{2}$ into the water, and it is neither much affected as a result of the synthesis or remineralization of organic matter [Paillard et al., 1993; Brewer and Peltzer, 2009]. However, we disregard any (potentially important) effects on atmospheric $\mathrm{CO}_{2}$ related to the introduction of cold waters to the surface ocean or to relative changes in the concentration of calcium carbonate during enhanced primary production; in section $\mathbf{5}$, we will come back to some of these issues.

[14] After arrival of deep water to the upper ocean, some of its inorganic carbon and nutrients are photosynthesized and converted into organic matter while some are left unused and returned back to the deep ocean during winter deep water formation (Figure 1). The equations for DIC, $c$, and DOC, $c_{r}$, in the upper ocean are

$$
\begin{aligned}
& \frac{\mathrm{d}(c V)}{\mathrm{d} t}=R-P+Q(G-c) \stackrel{\text { s.s. }}{\rightarrow} \quad P_{s}-R_{s}=Q_{s}\left(G_{s}-c_{s}\right), \\
& \frac{\mathrm{d}\left(c_{r} V\right)}{\mathrm{d} t}=P-R-Q c_{r} \quad \stackrel{s . s .}{\rightarrow} \quad P-R_{s}=Q_{s} c_{r, s},
\end{aligned}
$$

where $Q(t)$ is the volume transport (or overturning rate), $V$ is the upper ocean volume, $G(t)$ is the DIC concentration reaching the upper ocean through the returning MOC, and 
$R(t)$ and $P(t)$ are the remineralization and primary production of the upper ocean, respectively; the $s$ subindex denotes steady state (s.s.) conditions. In these expressions, the respiration comes from both the autotrophic $R_{\text {aut }}$ and heterotrophic $R_{\text {het }}$ communities, i.e., $R=R_{\text {aut }}+R_{\text {het }}$ (see Appendix A in the supporting information). A similar formulation was proposed by Pelegrí [2008] and Pelegrí et al. [2011] but with the important difference that the deep ocean input was taken as $Q c_{d}$ instead of $Q G$, with $c_{d}$ being the high-DIC concentration of the deep ocean; the deep ocean concentration was assumed constant and always larger than $c$ therefore conditioning the size and sign of $R-P$.

[15] Equations (1) and (2) are conservative for the upper ocean. Equation (2) shows that DOC is transferred from the upper to the deep ocean, where these materials will have plenty of time to remineralize. The model is largely idealized as it ignores any thermal and chemical ocean change, such as the deep-ocean carbonate system, and does not consider the high-nutrient and low-chlorophyll Southern Ocean. Further, it assumes the system is closed, i.e., it does not address processes such as iron fertilization, export of particulate organic matter, and changes in coastal erosion between glacial and interglacial cycles. Finally, it is not clear whether the concentrations of inorganic carbon and nutrients have significantly changed within the deep ocean in the past [Ganeshram et al., 1995; Sigman and Haug, 2003; Sigman et al., 2010], so the simplest hypothesis is to choose them constant. The model, therefore, focuses on the transformation between inorganic and organic matter within the upper ocean and on the exchange of dissolved carbon between the upper and deep ocean compartments through the MOC.

[16] The steady state form of equation (1) is identical to equation (A1) in the supporting information. This is a relevant result, as it suggests that the two-box ocean model may be understood as ruling the metabolic requirements for the upper ocean but with a changing pool of DIC: Equation (1) sets the fraction of solar energy used for photosynthetic transformation of DIC into DOC. For this to occur, the supply of DIC to the upper ocean has to switch between two different metabolic states, indistinctly supported by remote and local sources, with an exponential-like relaxation toward one single reference DIC value for each state.

\subsection{Nondimensional Formulation}

[17] As explained in section 1, one possible approach to reproduce two-state DIC transitions would be through a nondimensional relaxation-type equation, such as $\mathrm{d}(c V) / \mathrm{d} t=Q(g-c)$, where each state has its own $g$ value for the reference DIC. In this equation, $Q$ is inversely proportional to the relaxation time, i.e., a rapid transition corresponds to a large overturning rate and vice versa, and a constant $g$ sets the concentration level to be attained by the upper ocean if it remains sufficiently long within one single state. Equation (1) is turned into such an expression by simply letting $R-P=Q(g-G)$, i.e.,

$$
\frac{\mathrm{d} c}{\mathrm{~d} t}=Q(g-G)+Q(G-c)=Q(g-c) .
$$

[18] In equation (3), the total DIC supply $Q(g-c)$ has been decomposed into an advective source from the deep ocean
$Q(G-c)$ and a term arising from biological processes within the upper ocean $Q(g-G)$.

[19] Equation (3) is turned into nondimensional through the following scaling: $t=\tau_{0} t^{\prime}, c=c_{d} c^{\prime}, G=c_{d} G^{\prime} \equiv c_{d} \Gamma, g=$ $c_{d} g^{\prime} \equiv c_{d} \gamma, \quad Q=Q_{0} Q^{\prime} \equiv Q_{0} \varepsilon$, and $R-P=Q_{0} c_{d}\left(R^{\prime}-P^{\prime}\right)$, where $\tau_{0}$ is a glacial (or basal) time scale, $c_{d}$ is the DIC concentration of the deep ocean, and $Q_{0}=V / \tau_{0}$ is the basal recirculation rate, expressed in terms of the volume of the upper ocean $V$. Assuming an upper ocean of constant volume, the corresponding nondimensional equation becomes (dropping primes)

$$
\frac{\mathrm{d} c}{\mathrm{~d} t}=\varepsilon(\gamma-\Gamma)+\varepsilon(\Gamma-c)=\varepsilon(\gamma-c) .
$$

[20] The main advantage of this last equation is its simplicity, as the solution depends solely on two variables: the recirculation rate or inverse recirculation time $\varepsilon(t)$ and the concentration level $\gamma(t)$.

\section{Modeling the Antarctic Time Series}

\subsection{State Changes: Timing and Reference Concentrations}

[21] Rather than modeling the absolute value of DIC concentration in the upper ocean, we may look at its anomalies referred to some background state. Formally, this means we restrict our calculations to a relatively small DIC range where an approximate linear relation with atmospheric $\mathrm{CO}_{2}$ is expected; in practice, this allows us to use atmospheric $\mathrm{CO}_{2}$ anomalies as a proxy for changes in the upper ocean DIC. Specifically, we define $c=c_{0}$ $+\hat{c}, g=c_{0}+\hat{g}$, and $G=c_{0}+\hat{G}$, where $c_{0}$ is a constant value, and substitute back into equation (3), so that this equation (after dropping hats) becomes an anomaly equation, and equation (4) is the corresponding nondimensional anomaly relation. In the remaining of this paper, we will use these normalized anomalies and will refer to them simply as the nondimensional variables. Note that in order to recover dimensional values (see section 5), we need to dimensionalize the equations through an appropriate anomaly scale $\left(\Delta c_{d}\right.$ rather than $\left.c_{d}\right)$. Table 1 summarizes all dimensional parameters and variables, together with their nondimensional counterparts, appearing in the paper.

[22] In order to tune our DIC anomaly model, we use a nondimensional atmospheric $\mathrm{CO}_{2}$ signal anomaly, derived from the Vostok time series for the last four interglacial-glacial cycles, i.e., between years 432,375 and 20,750 before present. To produce this normalized anomaly time series, we employ the Lüthi et al. [2008] $\mathrm{CO}_{2}$ time series and follow three steps: (a) select the smallest and largest values of the original time series, (b) calculate the anomalies with respect to the smallest value, and (c) normalize these anomalies by the difference between the largest and smallest values. This normalized time series is shown in Figure 2 (top); it comprises four interglacialglacial cycles chronologically named cycles 1 to 4 , with cycle 4 the most recent one.

[23] To set the DIC supply, we use the two-state approximation: As the high state begins, the DIC requirements increase rapidly while as it ends, these requirements also decrease abruptly, so $\gamma(t)$ must resemble a step function. Specifically, the concentration level $\gamma$ temporarily rises from a basal-glacial 
Table 1. Summary of Parameters and Variables

\begin{tabular}{|c|c|c|c|c|}
\hline Parameters, Variables & Description & Dimensional & Scale & Nondimensional \\
\hline $\begin{array}{l}\text { Parameters from } \\
\text { ocean data }\end{array}$ & $\begin{array}{l}\text { Nowadays MOC transport ( } 22 \mathrm{~Sv} \text {, assumed to be the } \\
\text { same for all interglacial maxima) } \\
\text { Upper ocean volume }\left(4.7 \times 10^{17} \mathrm{~m}^{3}\right)\end{array}$ & $\begin{array}{c}Q_{\max } \\
V\end{array}$ & $Q_{0}$ & $\varepsilon_{\max }$ \\
\hline \multirow[t]{2}{*}{$\begin{array}{l}\text { Parameters from } \mathrm{CO}_{2} \\
\text { time series }\end{array}$} & $\begin{array}{c}\text { Beginning times for interglacial and glacial periods, } \\
\text { respectively } \\
\text { Time length of glacial and interglacial periods, } \\
\text { respectively } \\
\text { Time when the smoothed } \mathrm{CO}_{2} \text { time series reaches } \\
\text { maximum values }\end{array}$ & $\begin{array}{c}t_{1}, t_{2} \\
T_{\mathrm{g}}, T_{\mathrm{i}}=t_{2}-t_{1} \\
t_{\text {peak }}\end{array}$ & & \\
\hline & $\begin{array}{l}\text { Reference DIC concentration for deep ocean waters } \\
\text { reaching back the upper ocean through the MOC }\end{array}$ & $g$ & $c_{d}\left(\Delta c_{d}\right.$ for anomalies $)$ & $\gamma$ \\
\hline $\begin{array}{l}\text { Parameters as estimated } \\
\text { through GA }\end{array}$ & $\begin{array}{l}\text { Time when the MOC transport is maximum } \\
\text { (eventually set to } t_{2} \text { ) } \\
\text { Time when the MOC transport returns back to zero } \\
\text { (eventually set to time step after } t_{2} \text { ) } \\
\text { Glacial or basal time scale (inversely proportional to } \\
\text { the basal transport } Q_{0} \text { ) }\end{array}$ & $\begin{array}{c}t_{\max } \\
t_{3} \\
\tau_{0}=V / Q_{0}\end{array}$ & & \\
\hline Other parameters & $\begin{array}{l}\text { Non-dimensional deep ocean DIC reaching the } \\
\text { upper ocean at the beginning of the interglacial } \\
\text { Fraction of glacial-stored DOC available for } \\
\text { remineralization during the subsequent interglacial }\end{array}$ & $\begin{array}{c}\Gamma_{\mathrm{g}}=\Gamma\left(t=t_{1}\right) \\
\alpha\end{array}$ & & \\
\hline \multirow[t]{4}{*}{ Variables } & $\begin{array}{l}\text { Time } \\
\text { DOC concentration in the upper ocean } \\
\text { DIC concentration in the upper ocean } \\
\text { DIC concentration in deep ocean waters reaching } \\
\text { back to the upper ocean through the MOC }\end{array}$ & $\begin{array}{c}t \\
c_{\mathrm{r}} \\
c \\
G\end{array}$ & $\begin{array}{c}\tau_{0} \\
- \\
c_{d}\left(\Delta c_{d} \text { for anomalies }\right) \\
c_{d}\left(\Delta c_{d} \text { for anomalies }\right)\end{array}$ & $\begin{array}{l}t \\
- \\
c \\
\Gamma\end{array}$ \\
\hline & $\begin{array}{l}\text { MOC water transport } \\
\text { Exchange of DIC between the deep and upper } \\
\text { oceans or net DIC advective supply }\end{array}$ & $\underset{Q(G-c)}{Q}$ & $\begin{array}{c}Q_{0} \\
Q_{0} c_{\mathrm{d}}\end{array}$ & $\varepsilon(\stackrel{\varepsilon}{\varepsilon-c)}$ \\
\hline & $\begin{array}{l}\text { Upper ocean's primary production } \\
\text { Upper ocean's autotrophic respiration } \\
\text { Upper ocean's heterotrophic respiration } \\
\text { Net autotrophic community production, equals the } \\
\text { upper ocean's metabolic rate }\end{array}$ & $\begin{array}{c}P \\
R_{\text {aut }} \\
R_{\text {het }} \\
M=P-R_{\text {aut }}\end{array}$ & $\begin{array}{l}Q_{0} c_{\mathrm{d}} \\
Q_{0} c_{\mathrm{d}} \\
Q_{0} c_{\mathrm{d}} \\
Q_{0} c_{\mathrm{d}}\end{array}$ & $\begin{array}{c}P \\
R_{\text {aut }} \\
R_{\text {het }} \\
M=P-R_{\text {aut }}\end{array}$ \\
\hline & $\begin{array}{l}\text { Upper ocean's total respiration } \\
\text { Net community respiration, or negative net } \\
\text { community production }\end{array}$ & $\begin{array}{c}R=R_{\text {aut }}+R_{\text {het }} \\
R-P=Q(g-G)\end{array}$ & $\begin{array}{l}Q_{0} c_{\mathrm{d}} \\
Q_{0} c_{\mathrm{d}}\end{array}$ & $\begin{array}{l}R=R_{\text {aut }}+R_{\text {het }} \\
R-P=\varepsilon(\gamma-\Gamma)\end{array}$ \\
\hline
\end{tabular}

$\gamma_{g}$ (low DIC requirements) to an enhanced-interglacial level $\gamma_{i}$ (high DIC state):

$$
\gamma= \begin{cases}\gamma_{g}, & t<t_{1} \\ \gamma_{i}, & t_{1} \leq t<t_{2} \\ \gamma_{g}, & t_{2} \leq t\end{cases}
$$

where $\gamma_{g}$ and $\gamma_{i}$, respectively, set the glacial (rest) and interglacial (exercise) levels. We choose $\gamma_{g}=0$ and let $\gamma_{i}$ constant during each interglacial period but changing from one cycle to another (Figure 2 (top)). A constant $\gamma$ reflects the stability of the system, i.e., during one specific glacial or interglacial period, the system tends toward a reference point.

[24] The times for changing state, $t_{1}$ and $t_{2}$, and the reference levels during each interglacial period, $\gamma_{i}$, are specified by applying simple criteria to the smoothed $\mathrm{CO}_{2}$ time series. This smoothed series is obtained by low pass filtering the original time series: After several tests, we selected a 2 kyr filter for the interglacial period and a $7 \mathrm{kyr}$ filter for the glacial period. The interglacial start time $t_{1}$ corresponds to the last time when the derivative of the smoothed series becomes zero before the original time series overcomes some threshold, taken as $75 \%$ of the interglacial maximum value. An exception occurs if the last two minima are separated by less than $10 \mathrm{kyr}$; in this case $t_{1}$ is taken to be the average between these last two minima. Similarly, the end time $t_{2}$ is taken as the last time when the derivative of the smoothed series becomes zero before the original series decreases toward glacial values, again set as less than $75 \%$ of the interglacial maximum value. Figure 2 (bottom) shows a detailed view of cycle 4, with the $\mathrm{CO}_{2}$ original and smoothed series, indicating those times when the system changes from glacial to interglacial, $t_{1}$, and back to glacial, $t_{2}$. The interglacial $\gamma_{i}$ level is taken as the mean value of the $\mathrm{CO}_{2}$ smoothed time series between $t_{\text {peak }}$ and $t_{2}$, with $t_{\text {peak }}$ corresponding to the time when the smoothed series is maximum.

\subsection{Recirculation Rate}

[25] In a previous study [Pelegri et al., 2011], the recirculation rate was nondimensionalized as $Q=Q_{0} Q^{\prime}=Q_{0}(1+\varepsilon)$, and different $\varepsilon(t)$ functions, always linearly increasing or decreasing in time, were tested. It was found that the best data fit corresponded to $\varepsilon(t)=0$ during the glacial period and $\varepsilon(t)$ increasing through the interglacial. This relation pertained to a nondimensional basal glacial recirculation rate, $Q^{\prime}=1$, which was greatly enhanced during the interglacial, $Q^{\prime}=1+\varepsilon(t)$, with the maximum $\varepsilon(t)$ much greater than 1 . The interpretation was that the glacial state corresponds to a situation with a very slow MOC, bringing highly diluted deep ocean DIC to the upper ocean, while the interglacial state corresponds to an active $\mathrm{MOC}$, capable of bringing relatively undiluted bottom waters to the upper ocean. However, as 

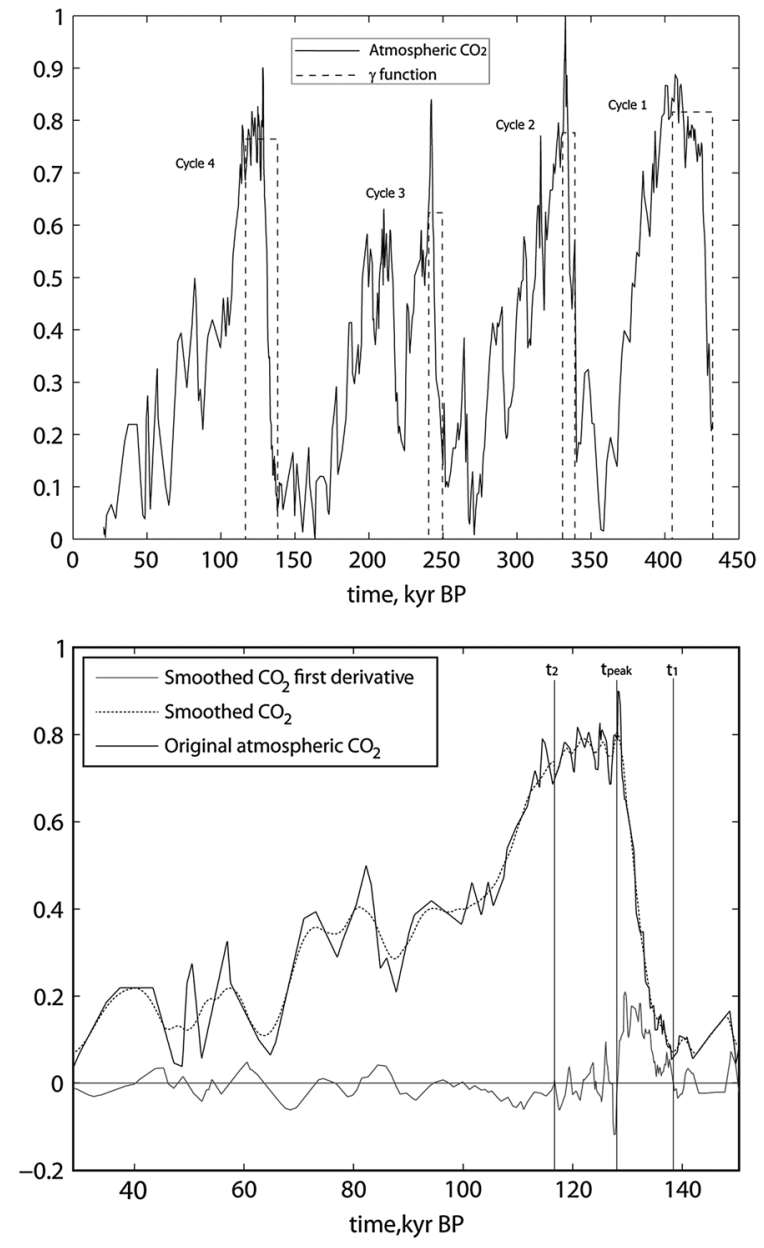

Figure 2. (top) Nondimensional normalized atmospheric $\mathrm{CO}_{2}$ anomaly as deduced from the Vostok's time series; the rectangles indicate the length and intensity of those periods with enhanced DIC supply. (bottom) Original and smoothed $\mathrm{CO}_{2}$ time series for cycle 4 , together with the time derivative of the smoothed time series, illustrating the timings for the enhanced-supply period. Adapted from Pelegrí et al. [2011].

argued in section $\mathbf{1}$, the dilution argument is counterintuitive as even a weak production of deep waters, if maintained during a long enough period, should eventually bring a high concentration level.

[26] Here we pursue an alternative and, we trust, more coherent interpretation: We propose the deep ocean becomes effectively blocked during glacial periods so that, in practice, no high DIC bottom waters reach the upper ocean. In this way, the change of DIC concentration within the upper ocean will only depend on the value of $P-R$. For this purpose, we nondimensionalize the recirculation rate as $Q=Q_{0} Q^{\prime} \equiv Q_{0} \varepsilon(t)$ and let $\varepsilon(t)$ change linearly with time between the glacial and interglacial periods. The numerical fit turns out to be very similar to that obtained by Pelegri et al. [2011] as all the difference in the current formulation lies on the interglacial recirculation rate being $\varepsilon(t)$ instead of $1+\varepsilon(t)$. The interpretation for the glacial period, however, is quite different: Rather than a weak recirculation rate $\left(Q^{\prime}=1\right)$, we think of the deep ocean as effectively blocked $\left(Q^{\prime}=0\right)$ so that no deep DIC sources are available. The decaying upper ocean DIC concentration is, therefore, not the result of diluted deep waters reaching the upper ocean but rather of DIC slowly being transformed into DOC $(P-R>0)$ within an isolated upper ocean.

[27] We examine the sensitivity of the model to simple expressions for the recirculation rate; specifically, we let $\varepsilon(t)$ increase linearly from $\varepsilon\left(t=t_{1}\right)=0$ to a maximum $\varepsilon\left(t=t_{\max }\right)=\varepsilon_{\max }$ and then back to $\varepsilon\left(t=t_{3}\right)=0$ (Figure 3 ). The time $t_{1}$ coincides with the beginning of the interglacial, the maximum recirculation takes place some time later, $t_{\max }>t_{1}$, and the recirculation is blocked again at some posterior time within the interglacial or the next glacial period, i.e., $t_{3} \geq t_{\max }$ can be smaller, equal, or larger than $t_{2}$. Notice $t_{\max }$ does not have to equal $t_{\text {peak }}$; the latter refers to the actual $\mathrm{CO}_{2}$ measurements and is obtained from the maximum interglacial value in the smoothed time series while the former concerns to the recirculation rate and is determined from the model.

\subsection{Best and Mean Value Predictions}

[28] The model is calibrated in two steps as described in Appendix B in the supporting information. In the first step, we discretely change parameters until we find a group of values that give an approximate fit to the data (Figure 4 (top)). In the second step, we apply a genetic algorithm (GA) to each interglacial-glacial cycle, initialized with the previously calculated values, to search for the set of parameters that provide the best fit to the data (Figure 4 (middle) and Table 2). Since these parameters change little from one cycle to another, we may calculate the mean parameters for the whole time series: $\bar{\gamma}_{i}=0.786$ and $\bar{\tau}_{0}=42.0 \mathrm{kyr}$ (or, alternatively, $\left.\bar{\varepsilon}_{\max }=60.0\right)$. With these values, and setting $t_{\max }=t_{2}$ and $t_{3}$ as the time step immediately after $t_{\text {max }}$, the model output still keeps a quite high correlation $\left(\mathrm{R}^{2}=0.78\right)$ to the data (Figure 4 (bottom)).

[29] This simple model, with only two parameters $\left(\bar{\gamma}_{i}\right.$ and $\left.\bar{\tau}_{0}\right)$ and the knowledge of the transition times $\left(t_{1}, t_{2}\right)$ for each cycle, is capable of reproducing the overall features of the last four interglacial-glacial cycles (Figure 4). In particular, it matches correctly the asymmetry between the rapid

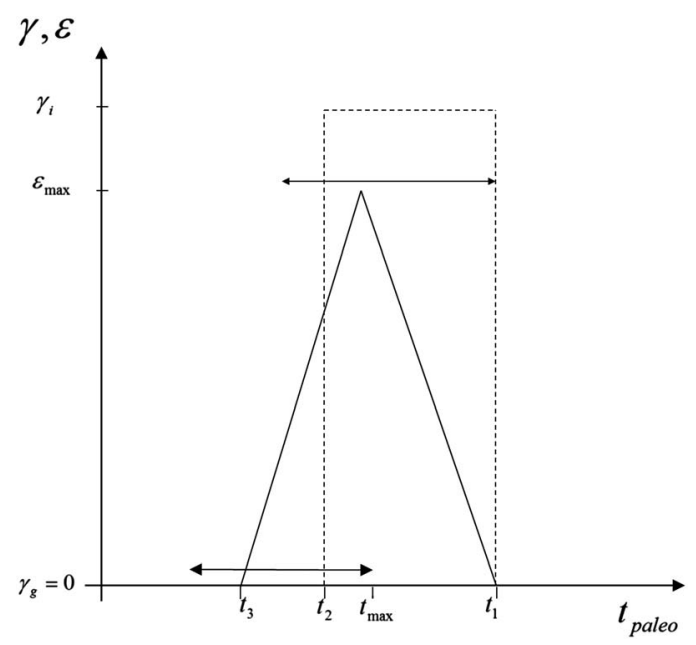

Figure 3. Schematics illustrating the search parameters used in the GA executions; the solid and dashed lines, respectively, correspond to the recirculation rate $\varepsilon$ and normalized energy function $\gamma$. 

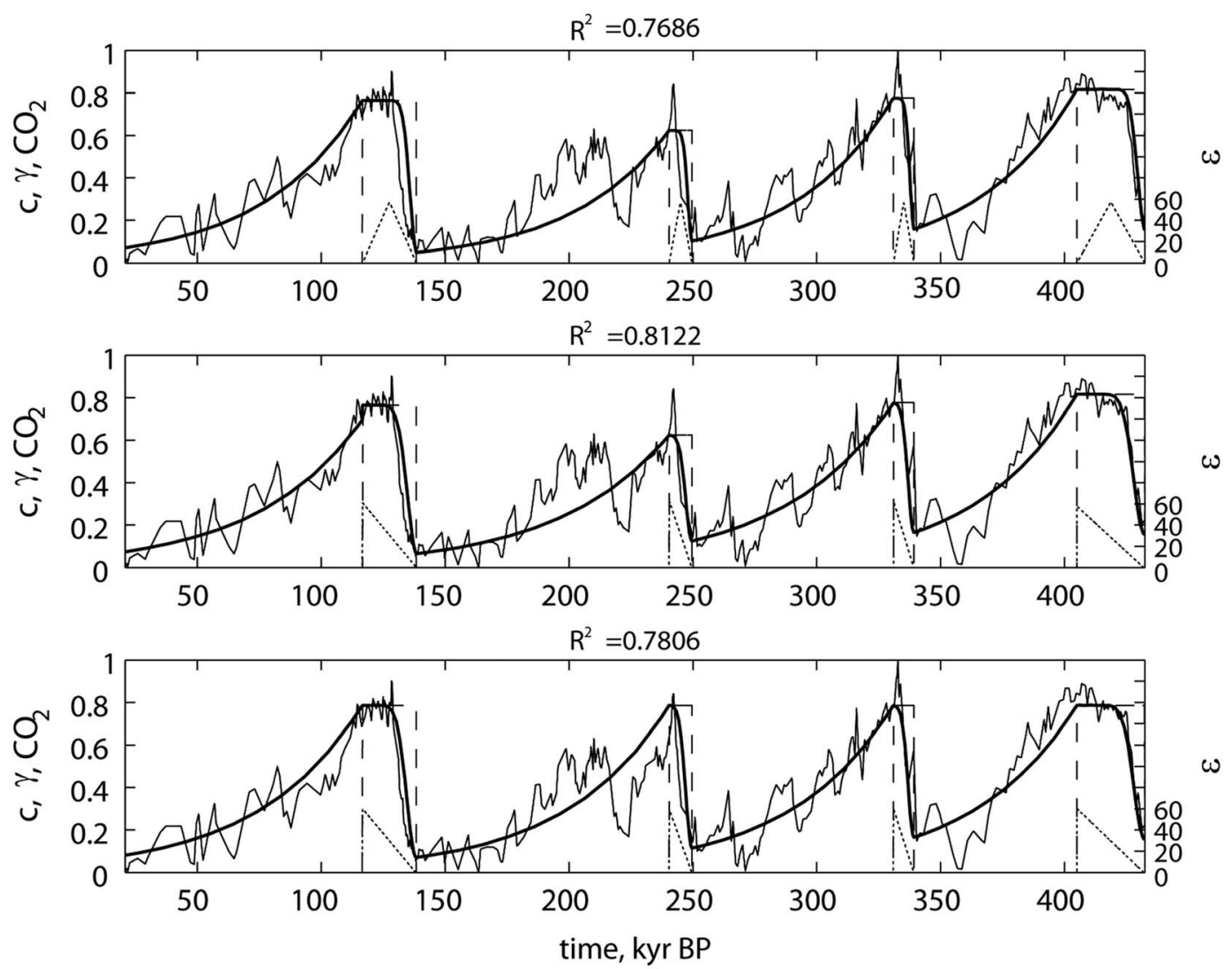

Figure 4. Normalized atmospheric $\mathrm{CO}_{2}$ anomaly (gray line) and model results of the nondimensional DIC in the upper ocean (black line) for three different cases; the panels also show the normalized energy function $\gamma$, which sets the changes in state, and the nondimensional recirculation rate $\varepsilon$ which increases rapidly during the interglacial period. (top) Model results for constant $\tau_{0}=40 \mathrm{kyr}, t_{\max }=\left(t_{1}+t_{2}\right) / 2$, and $t_{3}=t_{2}$. (middle) Model results for $\tau_{0}$ and $t_{\max }$, so that $\varepsilon_{\max } \equiv \varepsilon\left(t=t_{\max }\right)$, as obtained from the best GA execution, see Table 2. (bottom) Model results with the mean values for cycles 1,2 , and $4\left(\bar{\gamma}_{i}=0.786, \bar{\tau}_{0}=42.0 \mathrm{kyr}\right)$ and $t_{3}=t_{\max }=t_{2}$.

glacial-interglacial transition and the much slower interglacial-glacial decay. This is because the circulation rate $\varepsilon(t)$ rises linearly in time during the interglacial period, $\varepsilon(t)=$ $\varepsilon_{\text {max }}\left(t-t_{1}\right) /\left(t_{2}-t_{1}\right)$, which results in an effectively fast circulation rate (short relaxation time), while the transformation of DIC into DOC during the glacial cycles occurs at a very slow rate. The model certainly fails at simulating the abrupt changes, so the ocean-DIC-atmospheric $\mathrm{CO}_{2}$ correlation cannot become much larger than about 0.8 .

[30] The linear $\varepsilon(t)$ increase throughout the interglacial period is in qualitative agreement with evidences of a more intense MOC during interglacial periods than during glacial periods [Boyle and Keigwin, 1982; Shackleton et al., 1983; Labeyrie et al., 1992]. The interglacial MOC is assumed to have had the same intensity $Q_{\max }$ during all interglacial periods, equal to the current rate of deep water formation (estimated as $22 \mathrm{~Sv}$ ). The nondimensional MOC peak, $\varepsilon_{\max }$, is expressed as a multiple of a basal rate $Q_{0}$, defined in terms of the glacial relaxation time $\tau_{0}, \varepsilon_{\max }=Q_{\max } / Q_{0}=\left(Q_{\max } \tau_{0}\right) / V$. Its actual value depends on the volume of the upper ocean and the current rate of deep water formation, so its error bars are probably as large as a factor of three. For example, if

Table 2. The Top Three Rows Show the Parameters $\left(t_{1}, t_{2}\right.$, and $\left.\gamma_{i}\right)$ Obtained From the Analysis of the $\mathrm{CO}_{2}$ Time Series ${ }^{\mathrm{a}}$

\begin{tabular}{|c|c|c|c|c|c|}
\hline & Par\Cycle & 1 (Oldest) & 2 & 3 & 4 (Youngest) \\
\hline & $t_{1}(\mathrm{yrs} \mathrm{BP})$ & 432,375 & 339,275 & 249,675 & 138,375 \\
\hline & $t_{2}(\mathrm{yrs} \mathrm{BP})$ & 405,075 & 330,975 & 240,375 & 116,675 \\
\hline \multirow{3}{*}{ Best execution } & $\gamma_{i}$ & 0.816 & 0.776 & 0.624 & 0.765 \\
\hline & $\tau_{0}(\mathrm{kyr})\left(\varepsilon_{\max }\right)$ & $41.0(58.6)$ & $44.5(63.6)$ & $45.0(64.3)$ & $42.8(61.1)$ \\
\hline & $\left(t_{\max }-t_{1}\right) /\left(t_{2}-t_{1}\right)$ & 0.957 & 0.925 & 0.987 & 1.003 \\
\hline Mean \pm SD for 38 best executions & $\tau_{0}(\mathrm{kyr})\left(\varepsilon_{\max }\right)$ & $40.4 \pm 0.9(57.7 \pm 1.3)$ & $43.7 \pm 0.6(62.4 \pm 0.9)$ & $44.8 \pm 0.2(64.0 \pm 0.3)$ & $42.0 \pm 1.2(60.0 \pm 1.7)$ \\
\hline (correlation above 0.81 ) & $\left(t_{\max }-t_{1}\right) /\left(t_{2}-t_{1}\right)$ & $0.977 \pm 0.028$ & $0.923 \pm 0.021$ & $0.993 \pm 0.012$ & $1.004 \pm 0.002$ \\
\hline
\end{tabular}

\footnotetext{
${ }^{\text {a }}$ The remaining rows show the two model parameters $\left(\varepsilon_{\max }\right.$ or $\tau_{0}$ and $\left.\left(t_{\max }-t_{1}\right) /\left(t_{2}-t_{1}\right)\right)$ for the best data fit as obtained after $400 \mathrm{GA}$ executions for each interglacial-glacial cycle (rows 4 and 5, correlation 0.813 ), and for the mean \pm SD values of those executions (38) whose correlation with the observations is above 0.81 (rows 6 and 7).
} 
PELEGRÍ ET AL.: GLOBAL GLACIAL-INTERGLACIAL CONSTRAINTS

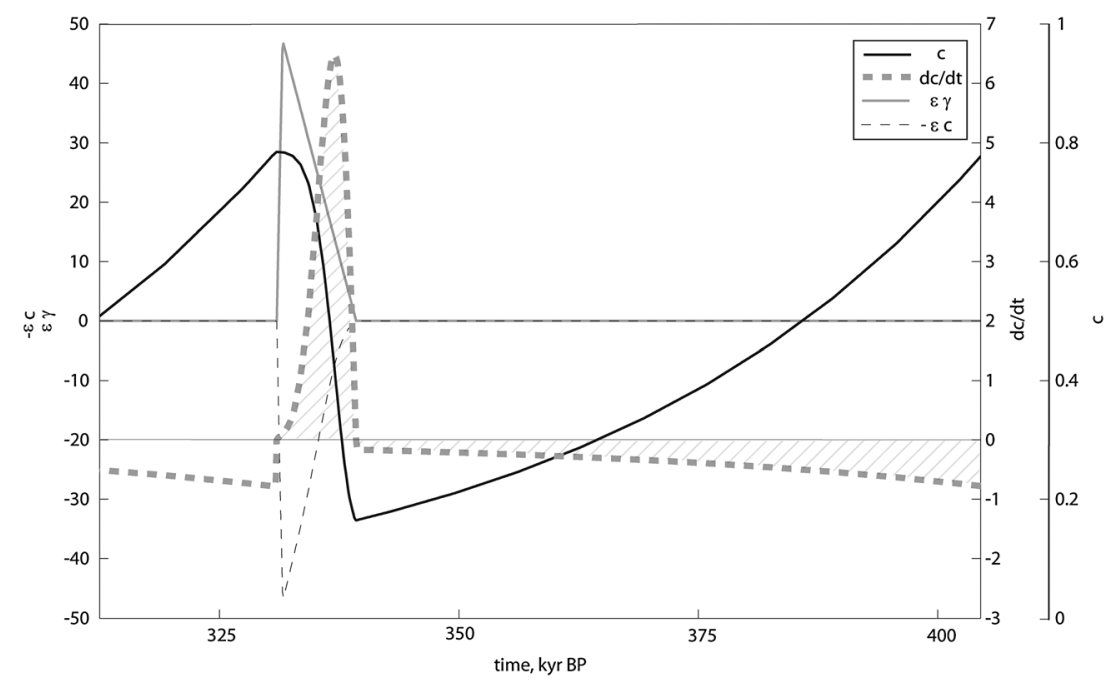

Figure 5. Model results for glacial cycle 1, interglacial cycle 2, and the start of glacial cycle 2 as obtained with the best GA execution (Table 2). The variables plotted are the DIC concentration in the upper ocean $c$ (black solid line), the total input rate $\varepsilon \gamma$ (gray solid line), and the output rate from the upper to the deep ocean $-\varepsilon c$ (dashed gray line); the thick dashed gray line corresponds to the time derivative of the DIC concentration $d c / d t$ and the shaded areas illustrate that condition (6) is approximately satisfied.

today's rate of deep water formation was $50 \mathrm{~Sv}$ (instead of $22 \mathrm{~Sv}$ ) and the upper ocean had a mean depth of $2000 \mathrm{~m}$ (instead of $1400 \mathrm{~m}$ ), $\varepsilon_{\max }$ would be about 20 . A high $\varepsilon_{\max }$ value, either 20 or 180 , simply reflects the different processes operating over the DIC budget: an intense MOC and net conversion of DOC into DIC during interglacial periods and net conversion of DIC into DOC during glacial periods.

\section{Balancing the Upper Ocean DOC Budget}

[31] The nondimensional concentration of DIC reaching the upper ocean through the MOC is set by $\Gamma(t)$. This variable is key to understanding how the DIC input splits between deep-ocean supply and remineralization of DOC within the upper ocean. We may use simple $\Gamma(t)$ dependences, together with DIC conservation arguments, in order to explore this partition. In this section, we will use a linear $\Gamma(t)$ dependence (Appendix $\mathrm{C}$ in the supporting information); further, in order to simplify the mathematics, we consider one full glacial-interglacial cycle with time zero set at the start of the glacial period.

[32] The essential argument is that, after one full glacialinterglacial cycle, the DIC in the upper ocean always approximately returns to its initial value. This means that the carbon budget is well balanced, i.e., $\int_{0}^{T_{g}+T_{i}}(\mathrm{~d} c / \mathrm{d} t) d t$ is approximately zero because the area below $\mathrm{d} c / \mathrm{d} t$ during the glacial approximately equals the area above $\mathrm{d} c / \mathrm{d} t$ during the posterior interglacial period (Figure 5):

$$
-\int_{0}^{T_{g}}(\mathrm{~d} c / \mathrm{d} t) \mathrm{d} t=\int_{T_{g}}^{T_{g}+T_{i}}(\mathrm{~d} c / \mathrm{d} t) \mathrm{d} t
$$

where $T_{g}$ and $T_{i}$, respectively, are the extent of the glacial and interglacial periods (setting $t=0$ at the start of the glacial gives $T_{g}=t_{1}$ and $T_{i}=t_{2}-t_{1}$ ). In our simple model, the observed oscillations are entirely justified in terms of pure net production during a glacial period and an equally large DIC supply (indistinctly coming from the deep ocean and/or upper ocean DOC remineralization) during the adjacent interglacial period. Equation (6) becomes

$$
\int_{0}^{T_{g}}(P-R) \mathrm{d} t=\int_{T_{g}}^{T_{g}+T_{i}}(R-P) \mathrm{d} t+\int_{T_{g}}^{T_{g}+T_{i}} \varepsilon(\Gamma-c) \mathrm{d} t .
$$

where $\Gamma(t)=\Gamma_{g}+\left(\gamma_{i}-\Gamma_{g}\right)\left(t-t_{1}\right) / T_{i}$ and the value at the start of the interglacial period, $\Gamma_{g}$, is given by equation (C5) (Appendix $\mathrm{C}$ in the supporting information).

[33] The DIC reaching the upper ocean at the start of the interglacial depends on the amount of DOC available for remineralization, specifically on the fraction $\alpha$ of DOC accumulated during the glacial period that is to be used during the subsequent interglacial. The sources and sinks of DIC within the upper ocean may be assessed for different values of $\alpha$, e.g., the smaller the $\alpha$, the larger will be the MOC contribution. Figure 6 zooms at the model solution at times before, during, and after an interglacial period for $\alpha=1.0$ and 0.5 (top and bottom panels, respectively). The rate of change of DIC, $\mathrm{d} c / \mathrm{d} t$, and the deep ocean net input, $\varepsilon(\Gamma-c)$, are computed from the model exact solutions (Appendix $\mathrm{C}$ in the supporting information). The net interglacial respiration is calculated as $R-P=\varepsilon\left(\gamma_{i}-\Gamma\right)$, and the net community primary production during the glacial stage is given by $R-P=-c$. At the start of the interglacial period, the deep ocean input may dominate the DIC budget, but later in the interglacial, because of high remineralization, the DIC concentration within the upper ocean temporarily exceeds those values arriving from the deep ocean, leading to a net loss of DIC through the MOC. We may see that as $\alpha$ decreases, the initial input of DIC from the deep ocean is more relevant, and the contribution from remineralization becomes less important. 


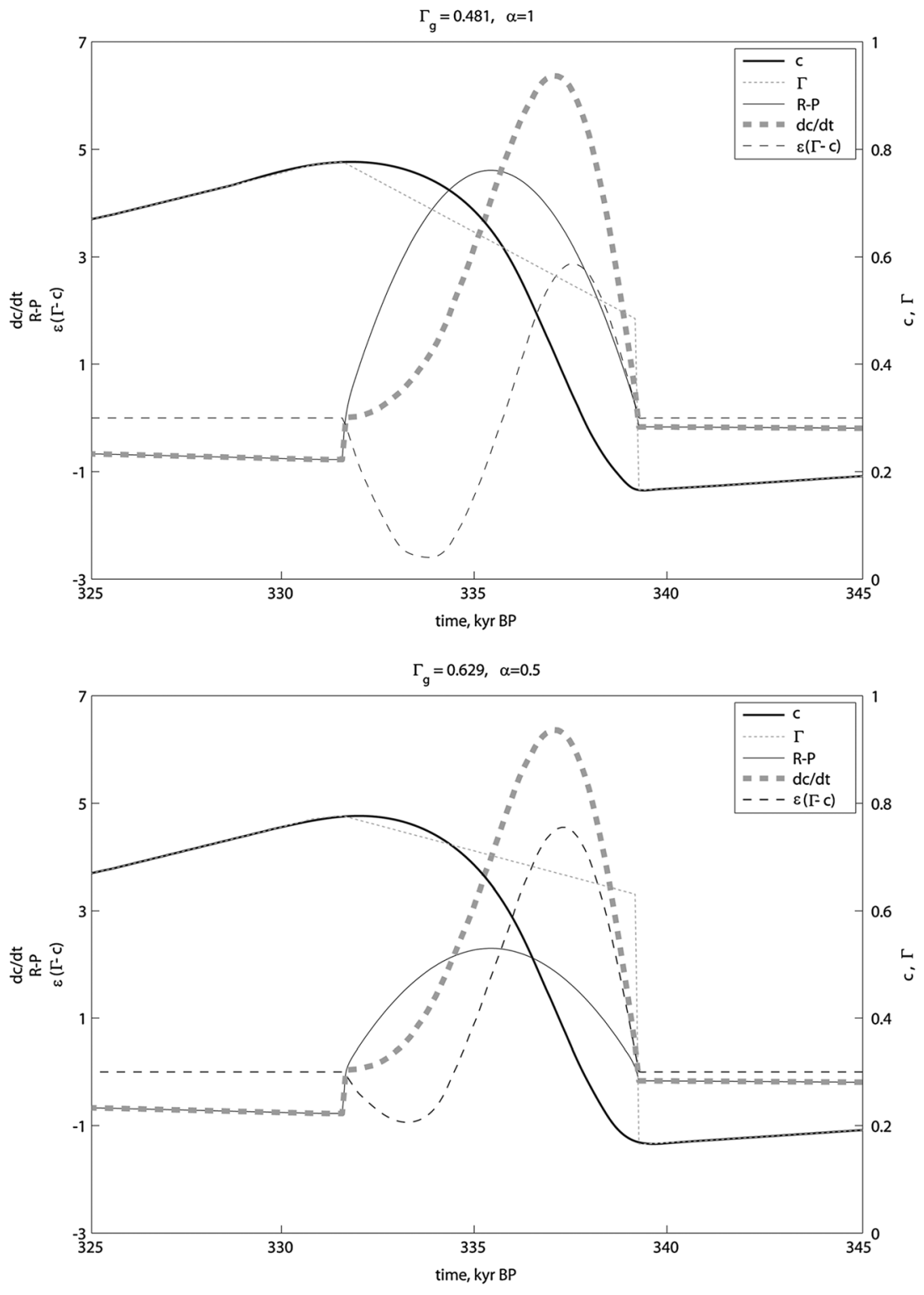

Figure 6. Model results zooming at interglacial cycle 2, as obtained with the best GA execution (Table 2), for (top) $\alpha=1$ and (bottom) $\alpha=0.5$. The variables plotted are the DIC concentration in the upper ocean $c$ (solid black line), the net input rate through the MOC $\varepsilon(\Gamma-c)$ (dashed gray line), the net rate of remineralization $R-P$ (solid gray line), and the time derivative of the DIC concentration $\mathrm{d} c / \mathrm{d} t$ (thick dashed gray line); the function $\Gamma(t)$ is plotted as a dotted line.

[34] The results, in particular the fractioning between deep ocean DIC supply and upper ocean remineralization during the interglacial period, depend on the expressions used for $\Gamma(t)$ and $\varepsilon(t)$ and on the portion $1-\alpha$ of DOC lost through the MOC. This is simply because we are solving one single equation with two unknowns. Further progress in this direction would require the joint solution of the DIC and DOC equations, subject to proper initial conditions.

\section{Discussion}

[35] There are evidences which suggest that two important properties of the upper ocean have been substantially different in glacial and interglacial periods: The MOC connection between the deep and upper oceans is enhanced during the interglacial period [Boyle and Keigwin, 1982; Shackleton et al., 1983; Labeyrie et al., 1992; Sigman and Boyle, 2000; Sigman et al., 2010], and during the glacial stage, in subantarctic waters, primary production exceeds respiration [Mortlock et al., 1991; Kumar et al., 1995; Harris et al., 1996; François et al., 1997; Robinson et al., 2005; Robinson and Sigman, 2008; Martínez-García et al., 2009]. Our simple model has shown that these evidences are consistent with a highly idealized scenario for glacial-interglacial changes in the supply of DIC to the upper ocean.

[36] At the beginning of the interglacial periods, there are two sources of net DIC supply to the upper ocean: The MOC brings deep ocean waters which have an excess DIC concentration, and the upper ocean DOC reservoir becomes progressively depleted as DOC is transformed into DIC 
Table 3. Values as Inferred From the Mean of the Best Executions in Table $2^{\mathrm{a}}$

\begin{tabular}{lccc}
\hline Cycles Glacial-Interglacial & $1-2$ & $2-3$ & $3-4$ \\
\hline$T_{g}(\mathrm{kyr})$ & 65.8 & 81.3 & 102.0 \\
$T_{i}(\mathrm{kyr})$ & 8.3 & 9.3 & 21.7 \\
$\gamma_{i}(\mathrm{kyr})\left(\varepsilon_{\max }\right)$ & 0.776 & 0.624 & 0.765 \\
$\tau_{0}$ & $40.4(62.4)$ & $43.7(64.0)$ & $44.8(60.0)$ \\
$\Gamma_{g}(\alpha=1)$ & 0.481 & 0.389 & 0.623 \\
$\Gamma_{g}(\alpha=0.9)$ & 0.511 & 0.412 & 0.637 \\
$\Gamma_{g}(\alpha=0.5)$ & 0.629 & 0.506 & 0.694 \\
\hline
\end{tabular}

${ }^{\mathrm{a} C y c l e s} 1-2,2-3$, and $3-4$ correspond to composites done using a glacialinterglacial full cycle ( $\tau_{0}$ belongs to the glacial decay, and $\varepsilon_{\max }$ corresponds to the interglacial period). All quantities except times are nondimensional.

through enhanced remineralization $(R>P)$. Both DIC sources reach maxima some time during the interglacial period, leading to the highest rate of DIC (and inorganic nutrients) increase but go back to zero by the end of the interglacial period as the system approaches a steady state. The MOC source goes to zero simply because the DIC in the upper ocean approaches the concentration of the deep ocean waters that reach back to the surface. The eventual decrease in the net DOC to DIC transformation within the upper ocean is related to the behavior of the metabolic rate, defined as the net autotrophic community production, $M \equiv P-R_{\text {aut }}$. During the (enhanced) interglacial period, the metabolic rate reaches toward a maximum value which equals the heterotrophic remineralization, i.e., $P-R$ tends to zero simply because both $P-R_{\text {aut }}$ and $R_{\text {het }}$ are equal and maxima.

[37] During the glacial periods, the upper and deep oceans are virtually disconnected, so very small amounts of DIC and inorganic nutrients are supplied from the deep ocean, and primary production relies on the interglacial upper ocean pool of DIC. During these periods, the upper ocean reached beyond some $2000 \mathrm{~m}$, dominated by the presence of the glacial North Atlantic intermediate waters (GNAIW) [Curry and Oppo, 2005; Lynch-Stieglitz et al., 2007]. It seems likely that the glacial upper ocean maintained a relatively rapid recirculation [Oppo and Lehman, 1993], alike that of the modern ocean, characterized by subduction of surface waters, DOC remineralization during their subsurface trip, and their return to the surface layers at high latitudes [Kawase and Sarmiento, 1985; Pelegri and Csanady, 1991; Pelegri et al., 2006]. Such a swift and long glacial recirculation would lead to an increase in the flux of regenerated inorganic nutrients reaching the euphotic layer and to a proportionally enhanced primary production. The machinery simply becomes more efficient, the only condition being that the thermocline recirculation takes longer than the time scale for remineralization. By the end of the glacial period, the amount of stored DOC would reach a maximum.

[38] Our simple model satisfies the condition that the DIC returns periodically to the initial condition, implying a tight relation between consecutive glacial and interglacial periods: A relatively long glacial period is followed by a proportionally intense interglacial (Figure 2 (top) and Table 3). If the upper ocean was locked, this would imply that the interglacial remineralization could balance the glacial net primary production. However, the interglacial upper ocean does drain both organic carbon and DIC to the deep ocean, meaning that both net (integrated over a glacial-interglacial cycle) primary production and DIC supply from the deep to the upper ocean are positive.
[39] The idea of long-term organic carbon storage in the oceans has recently become the focus of substantial interest (see reviews by Hansell et al. [2009] and Jiao et al. [2010]). Hansell et al. [2009] argue that the deep ocean observations of refractory DOC are consistent with lifetimes of about 15 $\mathrm{kyr}$, the same order as the relevant time scale during interglacial periods. This fits the idea that the large upper ocean pool of DOC, accumulated by the end of the glacial period, becomes a source of DIC and inorganic nutrients during the interglacial stage. A simple calculation may be carried out to assess potential DOC glacial-interglacial changes within the upper ocean reservoir. Nowadays, the DOC reservoir has been estimated to be about $700 \mathrm{Pg}$, with mean concentrations in the upper ocean of about $45 \mathrm{mmol} \mathrm{C} \mathrm{m}^{-3}$, while the DIC reservoir is some 55 times larger [Sundquist and Visser, 2003; Hansell et al., 2009]. Assuming that we are close to the end of the (anthropogenic unperturbed) interglacial, the above DOC balance implies that during the glacial maximum, the DOC reservoir could have been of the order of $2000 \mathrm{Pg} \mathrm{C}$, with upper ocean concentrations of about $132 \mathrm{mmol} \mathrm{C} \mathrm{m}^{-3}$ (Appendix D in the supporting information). This threefold DOC glacial increase would have taken place at the expense of the DIC reservoir, it decreasing by only about $1 \%$.

[40] It is important to emphasize that these figures should be only considered as gross indicators of potential glacial-interglacial changes in DOC stored within the upper ocean, as determined from the best fit of our idealized model to the observed atmospheric $\mathrm{CO}_{2}$ patterns. Our model has indeed ignored processes which could have a large impact on the DOC budget of the upper ocean. One such process is DOC return to the upper ocean through the MOC. Today's DOC concentrations in the deep ocean are about $35 \mathrm{mmol} \mathrm{C}$ $\mathrm{m}^{-3}$ [Hansell et al., 2009] so that today's DOC returned to the upper ocean (estimated as the product of the DOC concentration in the deep ocean times the transport of the MOC) amounts to about $0.3 \mathrm{Pg} \mathrm{C} \mathrm{yr}^{-1}$. The action of this process during the interglacial period could be expressed as effectively increasing the $\alpha$ parameter. Another neglected process is export of particulate organic carbon (POC) into the deep ocean, nowadays estimated at about $0.4 \mathrm{Pg} \mathrm{C} \mathrm{yr}^{-1}$ [Honjo et al., 2008]. During an interglacial period, this effect tends to compensate the previous one, effectively reducing the $\alpha$ parameter. Its role during the glacial period is much more difficult to appraise, it could either imply net primary production larger than here estimated or even the existence of a MOC-driven compensating deep ocean DIC supply. These two combined processes give an interglacial rate of about $0.1 \mathrm{Pg} \mathrm{C} \mathrm{yr}^{-1}$ export to the deep ocean, similar to our estimate for the DOC to DIC interglacial rate of transformation in the upper ocean, about $1300 \mathrm{Pg} \mathrm{C}$ in some 10,000 years.

[41] The solution of our model depends critically on the temporal changes of a highly idealized MOC, one that does not differentiate between northern and southern limbs and between advective and diffusive return paths. We have reduced the complexity of the actual MOC, either the present or past one, to one main mode of operation with regards to carbon air-sea exchange. Today's MOC, for example, is characterized by sinking of carbon-rich waters in subpolar regions and the return of DIC-rich waters, and $\mathrm{CO}_{2}$ outgassing, both in the equatorial Atlantic and in the Southern Ocean (the latter without considering anthropogenic effects [Gruber 
et al., 2012]). Our model suggests that during glacial periods, there was no such an analogous return path. The largest areas of the globe were dominated by the GNAIW and the formation of very dense bottom waters was localized at high latitudes in the Southern Ocean, taking place in relatively small surface areas but stretching worldwide under the GNAIW [Curry and Oppo, 2005; Lynch-Stieglitz et al., 2007]. The density difference between these water masses was very high, so negligible mixing took place between them [Watson and Naveira-Garabato, 2006; Skinner, 2009], and the Antarctic waters returned to the sea surface near its high-latitude formation areas, probably in regions with substantial sea ice capping; observed latitudinal differences in primary production may actually reflect the presence of these different water masses [Mortlock et al., 1991]. The atmospheric $\mathrm{CO}_{2}$ was therefore controlled by the transformations of carbon within the GNAIW, with DIC slowly turning into DOC because of positive net community production.

[42] The upper ocean has been defined as waters driven by wind or buoyancy pumping with relatively short recirculation times (order 10 years), for the glacial period corresponding to the quite thick GNAIW. The above considerations are not in conflict with our idealization of an upper ocean of constant volume, as our nondimensional results depend only on the size of the interglacial volume (section 2.1). It is true, however, that this variability has to be taken into account when estimating the glacial maximum DOC concentrations: A doubling of the glacial size would mean halving the glacial increase in DOC, i.e., the upper ocean DOC concentrations at the end of the glacial period would have been about 89 rather than $132 \mathrm{mmol} \mathrm{C} \mathrm{m}^{-3}$. Clearly, in order to obtain more accurate results, our model would require both including a third box to represent the Southern Ocean, as early done by Sarmiento and Toggweiler [1984] and Siegenthaler and Wenk [1984], and allowing a variable-size upper ocean.

[43] We wish to emphasize that by no means has our approach intended to be a comprehensive approximation to the Earth system. The two-box model, with the upper ocean in equilibrium with the atmosphere, has definitely been inspired on the way energy is distributed and transformed in living beings as they change their metabolic state [Pelegrí, 2008]. The approach has focused on a few global variables, therefore ignoring any spatial variability, in a similar way as the health of a living being is quickly assessed through a handful of physiological variables. In particular, we have explored the potential relevance of both a changing MOC and a varying pool of dissolved organic matter in the upper ocean. We believe this perception, yet far from complete, may eventually lead to fundamentally new perspectives in our understanding of the Earth system.

[44] Many other processes may have certainly played a very significant role in controlling the glacial-interglacial variations (see reviews by Sigman and Boyle [2000], Paillard [2001], Kohfeld et al. [2005], Sarmiento and Gruber [2006], and Sigman et al. [2010]). For example, Kohfeld et al. [2005] pointed that increased glacial export production could account for about half the observed $\mathrm{CO}_{2}$ changes, and Toggweiler [1999] justified the full range in terms of MOC variations combined with the calcium carbonate compensation mechanism. Their description goes well beyond our objectives, but it is worth to end this section with a brief mention of the most promising candidates.
[45] Our model's biological pump has been most rudimentary, disregarding particulate matter and making no distinction between plankton species, and the carbonate pump has been totally neglected. Shifts in the dominant plankton types may have had important consequences on the ocean's DIC. For example, our proposition of increased glacial net production is consistent with a glacial increase in biological rain; if such an increase was accompanied by a reduced calciumcarbonate to organic-carbon ratio, it would have driven an important decrease in atmospheric $\mathrm{CO}_{2}$ [Sigman and Boyle, 2000]. The physical pump has neither considered any feedback mechanisms, such as how changes in surface temperature (brought about by the MOC) may affect the incorporation of heat to the upper ocean. Other mechanisms playing a potential role in the air-sea $\mathrm{CO}_{2}$ equilibrium have also been completely ignored: wind-driven upwelling in the Southern Ocean related to the meridional shift in the westerlies, changes in ice coverage and iron fertilization at high latitudes, and dust fluxes to the subtropical gyres. Finally, in our model, the upper ocean DIC concentration is controlled by one single glacial (DIC to DOC transformation) and two interglacial (DOC respiration and deep-ocean supply) processes. In particular, the two interglacial processes are assumed to begin at the same time; however, it is possible that these interglacial mechanisms had not operated simultaneously but sequentially. Similarly, during the glacial period, the DIC to DOC transformation may had been complemented with other processes, for example, the initial MOC interruption could have been followed by iron fertilization of the Southern Ocean [Sigman et al., 2010].

\section{Concluding Remarks}

[46] We have proposed a two-box ocean model for DIC in the upper ocean, with simple parameterizations for the intensity of the MOC and the net community production during glacial and interglacial periods, whose solution displays exponential decays toward reference DIC values. The model is tuned with a GA in order to obtain the basal (or glacial) time scale $\tau_{0}$ and the time dependence of the interglacial recirculation rate anomaly $\varepsilon(t)$ that provide the best model fit to the data. The model, despite its simplicity, does well at reproducing the atmospheric $\mathrm{CO}_{2}$ glacial-interglacial pattern, with data correlations close to 0.8 when only two parameters (basal time scale and interglacial DIC level) and the state-switching times are specified. The model predicts a relatively long (basal) glacial relaxation period, $42 \mathrm{kyr}$, which is related to the decay time for the conversion of DIC into DOC, surprisingly similar to the period of the Earth's obliquity cycle. It also predicts interglacial relaxation periods 1 to 2 orders of magnitude shorter, associated to high heterotrophic respiration and a swift MOC.

[47] The metabolic rate of the ocean system has been identified with the net primary production of the autotrophic community. This concept has allowed us to explore the idea that the ocean (and probably the Earth) system switches between two different metabolic states, characterized by quite different rates of inorganic carbon and nutrient supply to the upper ocean and, therefore, photosynthetic solar energy transformation. As the system shifts to an enhanced (interglacial) state, the DIC and inorganic nutrients are supplied by the deep ocean through a progressive increase in the MOC. This match is not attained instantly, so the system must resource to inorganic 
nutrients and carbon resulting from oxidation of organic matter. The metabolic rate experiences a large increase, but the heterotrophic respiration is so large that total respiration exceeds primary production. When the system returns to the basal (glacial) state, it slowly recovers its reserves of organic matter. During this period, the metabolic rate, despite being small, exceeds the heterotrophic respiration.

[48] We have not proposed what may be the mechanisms that lead to such substantial changes in ocean state. Whatever the triggering mechanisms, for a review, see Paillard and Parrenin [2004], they must have intense positive feedback within the Earth system. Instead, our simple model has focused on assessing what the atmospheric $\mathrm{CO}_{2}$ glacial-interglacial patterns may be telling us about the carbon transformations taking place within the upper ocean. Our results suggest that upper ocean DIC supply during an interglacial period, both from the deep ocean and through DOC remineralization, equals the DIC employed through net primary production during the adjacent glacial period. A novel element is the role played by dissolved organic matter in the upper ocean as a proximal and relatively fast source of inorganic carbon and nutrients, building up during glacial periods and becoming available through enhanced heterotrophic respiration during the interglacial times. This mode of operation is indicative of the existence of a pulsating homeostatic organization, e.g., the longer and deeper a glacial period, the more intense will be the next interglacial.

[49] Analogous temporal patterns have been observed in other complex systems, as they change between two distinct metabolic states [Scheffer et al., 2001, 2009; Dakos et al., 2008]. For example, as mammals begin exercise, they experience changes in the rate of oxygen and nutrient supply to the different organs, coming from both nearby (reserves within cells) and remote (brought by the circulatory system) sources [Pelegri, 2008]. The corollary of this study may possibly be that future work on the climate of the Earth system shall benefit from observations of the organization and response of other complex systems, such as living beings, hence using physiology as a source of inspiration.

[50] Acknowledgments. We sincerely thank our colleagues for many useful comments, particularly Xosé Álvarez-Salgado, Eva Calvo, Marta Estrada, Carmen Herrero, Denny Kirwan, Celia Marrasé, Carles Pelejero, and Fiz Pérez. We would also like to extend our gratitude to our reviewers for numerous constructive suggestions, including Christopher Charles, the journal's chief editor. This work has been funded through projects MOC2 (CTM2008-06438-C02) and TIC-MOC (CTM2011-28867) of the R+D Spanish research program and through project Fisiocean (PIF08-006-1) of CSIC's frontier program. PDLF has been partly supported through a FI-AGAUR fellowship from the Catalan government.

\section{References}

Anderson, L. A., and J. L. Sarmiento (1994), Redfield ratios of remineralization determined by nutrient data analysis, Global Biogeochem. Cycles, 8, 65-80.

Boyle, E. A., and L. D. Keigwin (1982), Deep circulation of the North Atlantic over the last 200,000 years: Geochemical evidence, Science, 218, 784-787.

Brewer, P. G., and E. T. Peltzer (2009), Limits to marine life, Science, 324, 347-348.

Broecker, W. S. (1982a), Glacial to interglacial changes in ocean chemistry, Progr. Oceanogr., 11, 151-197.

Broecker, W. S. (1982b), Ocean chemistry during glacial time, Geochim. Cosmochim. Acta, 46, 1689-1706.

Broecker, W. S. (1991), The great ocean conveyor, Oceanography, 4, 78-89.
Broecker, W. S., and T.-H. Peng (1987), The role of $\mathrm{CaCO}_{3}$ compensation in the glacial to interglacial atmospheric $\mathrm{CO}_{2}$ change, Global Biogeochem. Cycles, 1, 15-29.

Calder, N. (1974), Arithmetic of ice ages, Nature, 252, 216-218.

Curry, W. B., and D. W. Oppo (2005), Glacial water mass geometry and the distribution of $\delta^{13} \mathrm{C}$ of $\Sigma \mathrm{CO}_{2}$ in the western Atlantic Ocean, Paleoceanography, 20, PA1017, doi:10.1029/2004PA001021.

Dakos, V., M. Scheffer, E. H. van Nes, V. Brovkin, V. Petoukhov, and H. Held (2008), Slowing down as an early warning signal for abrupt climate change, Proc. Natl. Acad. Sci. U. S. A., 105, 14,308-14,312.

François, R., M. A. Altabet, E.-F. Yu, D. M. Sigman, M. P. Bacon, M. Frank, G. Bohrman, G. Bareille, and L. Labeyrie (1997), Contribution of Southern Ocean surface-water stratification to low atmospheric $\mathrm{CO}_{2}$ concentrations during the last glacial period, Nature, 389, 929-935.

Ganeshram, R. X., T. F. Pedersen, S. E. Calvert, and J. W. Murray (1995), Large changes in oceanic nutrient inventories from glacial to interglacial periods, Nature, 376, 755-758.

García-Olivares, A., and C. Herrero (2012), Fitting the last Pleistocene delta $\mathrm{O}-18$ and $\mathrm{CO}_{2}$ time-series with simple box models, Sci. Mar., 76S1, 209-218.

García-Olivares, A., and C. Herrero (2013), Simulation of glacial-interglacial cycles by simple relaxation models: Consistency with observational results, Clim. Dyn., 41, 1307-1331.

Gruber, N., et al. (2012), Oceanic sources, sinks, and transport of atmospheric $\mathrm{CO}_{2}$, Global Biogeochem. Cycles, 23, GB1005, doi:10.1029/ 2008 GB003349.

Hansell, D. A., C. A. Carlson, D. J. Repeta, and R. Schlitzer (2009), Dissolved organic matter in the ocean: A controversy stimulates new insights, Oceanography, 22, 202-211.

Harris, P. G., M. Zhao, A. Rosell-Melé, R. Tiedemann, M. Sarnthein, and J. R. Maxwell (1996), Chlorin accumulation as a proxy for Quaternary marine primary productivity, Nature, 383, 63-65.

Hogg, A. M. (2008), Glacial cycles and carbon dioxide: A conceptual model, Geophys. Res. Lett., 35, L01701, doi:10.1029/2007GL032071.

Honjo, S., S. J. Manganini, R. A. Krishfield, and R. Francois (2008), Particulate organic carbon fluxes to the ocean interior and factors controlling the biological pump: A synthesis of global sediment trap programs since 1983, Progr. Oceanogr., 76, 217-285.

Imbrie, J., and J. Z. Imbrie (1980), Modelling the climatic response to orbital variations, Science, 207, 943-953.

Imbrie, J., et al. (1993), On the structure and origin of major glaciation cycles 2. The 100,000-year cycle, Paleoceanography, 8, 699-735.

Jiao, N., G. J. Herndl, D. A. Hansell, R. Benner, G. Kattner, S. W. Wilhelm, D. L. Kirchman, M. G. Weinbauer, T. Luo, and F. Chen (2010), Microbial production of recalcitrant dissolved organic matter: Long-term carbon storage in the global ocean, Nat. Rev. Microbiol., 8, 593-599.

Kawase, M., and J. L. Sarmiento (1985), Nutrients in the Atlantic thermocline, J. Geophys. Res., 90, 8961-8979.

Knox, F., and M. McElroy (1984), Changes in atmospheric $\mathrm{CO}_{2}$ influence of the marine biota at high latitude, J. Geophys. Res., 89, 4629-4637.

Kohfeld, K. E., C. Le Quére, S. P. Harrison, and R. F. Anderson (2005), Role of marine biology in glacial-interglacial $\mathrm{CO}_{2}$ cycles, Science, 308, 74-78.

Kumar, N., R. F. Anderson, R. A. Mortlock, P. N. Froelich, P. Kubik, B. Dittrichhannen, and M. Suter (1995), Increased biological productivity and export production in the glacial Southern Ocean, Nature, 378, 675-680.

Labeyrie, L. D., J. C. Duplessy, J. Duprat, A. Juillet-Leclerc, J. Moyes, E. Michel, N. Kallel, and N. J. Shackleton (1992), Changes in the vertical structure of the North Atlantic Ocean between glacial and modern times, Quaternary Sci. Rev., 11, 401-413.

Lüthi, D., et al. (2008), High-resolution carbon dioxide concentration record $650,000-800,000$ years before present, Nature, 378, 379-382.

Luyten, J. R., and H. Stommel (1986), Gyres driven by combined wind and buoyancy flux, J. Phys. Oceanogr., 16, 1551-1560.

Lynch-Stieglitz, J., et al. (2007), Atlantic meridional overturning circulation during the Last Glacial Maximum, Science, 316, 66-69.

Martin, J. (1990), Glacial-Interglacial $\mathrm{CO}_{2}$ change: The iron hypothesis, Paleoceanography, 5, 1-13.

Martínez-García, A., A. Rosell-Melé, W. Geibert, R. Gersonde, P. Masqué, V. Gaspari, and C. Barbante (2009), Links between iron supply, marine productivity, sea surface temperature, and $\mathrm{CO}_{2}$ over the last $1.1 \mathrm{Ma}$, Paleoceanography, 24, PA1207, doi:10.1029/2008PA001657.

Mortlock, R. A., C. D. Charles, P. N. Froelich, M. A. Zibello, J. Saltzman, J. D. Hays, and L. H. Burckle (1991), Evidence for lower productivity in the Antarctic Ocean during the last glaciation, Nature, 351, 220-223.

Oppo, D. W., and S. J. Lehman (1993), Mid-depth circulation of the subpolar North Atlantic during the Last Glacial Maximum, Science, 259, 1148-1152.

Paillard, D. (1998), The timing of Pleistocene glaciations from a simple multiple-state climate model, Nature, 391, 378-381. 
Paillard, D. (2001), Glacial cycles: Toward a new paradigm, Rev. Geophys., $39,325-346$.

Paillard, D., and F. Parrenin (2004), The Antarctic ice sheet and the triggering of deglaciations, Earth Planet. Sci. Lett., 227, 263-271.

Paillard, D., M. Ghil, and H. Le Treut (1993), Dissolved organic matter and the glacial-interglacial $\mathrm{pCO}_{2}$ problem, Global Biogeochem. Cycles, 7, 901-914.

Peacock, S., E. Lane, and J. M. Restrepo (2006), A possible sequence of events for the generalized glacial-interglacial cycle, Global Biogeochem. Cycles, 20, GB2010, doi:10.1029/2005GB002448.

Pelegrí, J. L. (2008), A physiological approach to oceanic processes and glacial-interglacial changes in atmospheric $\mathrm{CO}_{2}$, Sci. Mar., 72, 125-202.

Pelegrí, J. L., and G. T. Csanady (1991), Nutrient transport and mixing in the Gulf Stream, J. Geophys. Res., 96, 2577-2583.

Pelegrí, J. L., A. Marrero-Díaz, and A. W. Ratsimandresy (2006), Nutrient irrigation of the North Atlantic, Progr. Oceanogr., 70, 366-406.

Pelegrí, J. L., R. Olivella, and A. García-Olivares (2011), A simple metabolic model of glacial-interglacial energy supply to the upper ocean, Earth Syst. Dyn. Disc., 2, 271-313.

Petit, J. R., et al. (1999), Climate and atmospheric history of the past 420,000 years from the Vostok ice core, Antarctica, Nature, 399, 429-436.

Raymo, M. E., and K. Nisancioglu (2003), The 41 kyr world: Milankovitch's other unsolved mistery, Paleoceanography, 18, 1011, doi:10.1029/2002 PA000791.

Robinson, R. S., and D. M. Sigman (2008), Nitrogen isotopic evidence for a poleward decrease in surface nitrate within the ice age Antarctic, Quat. Sci. Rev., 27, 1076-1090.

Robinson, R., D. Sigman, P. DiFiore, M. Rohde, T. Mashiotta, and D. Lea (2005), Diatom-bound ${ }^{15} \mathrm{~N} /{ }^{14} \mathrm{~N}$ : New support for enhanced nutrient consumption in the ice age subantarctic, Paleoceanography, 20, PA3003, doi:10.1029/2004PA001114.

Sarmiento, J. L., and N. Gruber (2006), Ocean Biogeochemical Dynamics, Princeton University Press, Princeton.

Sarmiento, J. L., and J. R. Toggweiler (1984), A new model for the role of the oceans in determining atmospheric $P \mathrm{CO}_{2}$, Nature, 308, 621-624.

Scheffer, M., S. Carpenter, J. A. Foley, C. Folke, and B. Walkerk (2001), Catastrophic shifts in ecosystems, Nature, 413, 591-596.

Scheffer, M., J. Bascompte, W. A. Brock, V. Brovkin, S. R. Carpenter, V. Dakos, H. Held, E. H. van Nes, M. Rietkerk, and G. Sigihara (2009), Early-warning signals for critical transitions, Nature, 461, 53-59.

Shackleton, N. J., J. Imbrie, and M. A. Hall (1983), Oxygen and carbon isotope record of East Pacific core V19-30: Implications for the formation of deep-water in the late Pleistocene North-Atlantic, Earth Planet. Sci. Lett., 65, 233-244.

Siegenthaler, U., and J. L. Sarmiento (1993), Atmospheric carbon dioxide and the ocean, Nature, 365, 119-125.

Siegenthaler, U., and T. Wenk (1984), Rapid atmospheric $\mathrm{CO}_{2}$ variations and ocean circulation, Nature, 308, 624-626.

Siegenthaler, U., et al. (2005), Stable carbon cycle-climate relationship during the Late Pleistocene, Science, 310, 1313-1317.

Sigman, D. M., and E. A. Boyle (2000), Glacial/interglacial variations in atmospheric carbon dioxide, Nature, 407, 859-869.

Sigman, D. M., and G. H. Haug (2003), The biological pump in the past, in Treatise on Geochemistry, vol. 6, edited by D. Holland and K. K. Turekian, pp. 491-528, Elsevier, London.

Sigman, D. M., M. P. Hain, and G. H. Haug (2010), The polar ocean and glacial cycles in atmospheric $\mathrm{CO}_{2}$ concentration, Nature, 466, 47-55.

Skinner, L. C. (2009), Glacial-interglacial atmospheric $\mathrm{CO}_{2}$ change: A possible "standing volume" effect on deep-ocean carbon sequestration, Clim. Past, 5, 537-550.

Stephens, B. B., and R. F. Keeling (2000), The influence of Antarctic sea ice on glacial-interglacial $\mathrm{CO}_{2}$ variations, Nature, 404, 171-174.

Stommel, H. (1961), Thermohaline convection with two stable regimes of flow, Tellus, 13, 224-230.

Stommel, H. (1979), Determination of water mass properties of water pumped down from the Ekman layer to the geostrophic flow below, Proc. Natl. Acad. Sci. U. S. A., 76, 3051-3055.

Sundquist, E. T., and K. Visser (2003), The geological history of the carbon cycle, in Treatise on Geochemistry, vol. 6, edited by D. Holland and K. K. Turekian, pp. 425-472, Elsevier, London.

Toggweiler, J. R. (1999), Variation of atmospheric $\mathrm{CO}_{2}$ by ventilation of the ocean's deepest water, Paleoceanography, 14, 571-588.

Toggweiler, J. R., J. L. Russell, and S. R. Carson (2006), Midlatitude westerlies, atmospheric $\mathrm{CO}_{2}$, and climate change during ice ages, Paleoceanography, 21, PA2005, doi:10.1029/2005PA001154.

Watson, A. J., and L. Maddock (1993), A geophysiological model for glacial-interglacial oscillations in the carbon and phosphorus cycles, in Scientists on Gaia: Proceedings of the AGU Chapman Conference on the Gaia Hypothesis, edited by S. H. Schneider and P. J. Boston, pp. 240-246, MIT press, Cambridge.

Watson, A. J., and A. C. Naveira-Garabato (2006), The role of Southern Ocean mixing and upwelling in glacial-interglacial atmospheric $\mathrm{CO}_{2}$ change, Tellus, 58B, 73-87. 